\title{
DESENVOLVIMENTO DE UMA MACRO EM VBA QUE ESTENDE AS CAPACIDADES DO CIVIL 3D PARA PROJETOS DE CONDUTAS ADUTORAS
}

\author{
Luís Ribeirinho ${ }^{(1)}$
}

(1) TPF - CONSULTORES DE ENGENHARIA E ARQUITETURA, S.A., Lisboa

\begin{abstract}
Resumo
As condutas adutoras inserem-se na categoria das infraestruturas lineares e, nesse sentido, há vantagens no desenvolvimento do seu projeto em Civil 3D. Contudo, ao contrário do que acontece noutras infraestruturas lineares, sobretudo ligadas aos transportes, nas condutas adutoras a relação entre a planta e o perfil longitudinal não se estabelece pela sua quilometragem, mas antes pela identificação dos seus perfis notáveis. A identificação desses pontos, dos vértices das curvas em desenvolvimento, das ventosas, ou das descargas de fundo, recorrendo a ferramentas nativas do Civil 3D, não é simples e, por isso, o procedimento que se adotava passava por definir a conduta em Civil 3D, mas os restantes elementos em AutoCAD com recurso a rotinas Lisp. Esta definição era morosa e não oferecia garantias da coerência entre as diferentes peças desenhadas.

Para a resolução do problema referido, a solução encontrada, e que se aborda no presente artigo, envolveu o desenvolvimento de uma macro em VBA que corre no Civil 3D e que acede aos objetos do modelo para gerar a informação em falta. Foi desenvolvida uma interface simples que permite ao utilizador controlar as ações a executar, nomeadamente, identificação dos perfis ou dos vértices, na planta ou no perfil longitudinal, criação das tabelas de coordenadas desses pontos por folha, indicação dos ângulos dos acessórios comerciais, colocação automática das ventosas e descargas de fundo, com possibilidade de acrescentar ou retirar manualmente qualquer um dos acessórios.
\end{abstract}

\section{Introdução}

No âmbito da implementação BIM na TPF Consultores, tem havido um investimento significativo nos projetos de abastecimento de água, não só pela recetividade da equipa da TPF Consultores dedicada a este tipo de projetos, mas também pelo interesse manifestado pelos clientes. Foi neste contexto que os referidos projetistas identificaram uma oportunidade de melhoria no que diz respeito ao projeto de condutas adutoras. As obras pontuais, como reservatórios ou estações elevatórias, já estavam a ser desenvolvidas na empresa com recurso à metodologia BIM, mas as obras lineares, como as condutas adutoras, ainda não tinham 
transitado completamente para esta forma de trabalho. Foi então que a equipa de projeto abordou o Núcleo de Inovação da TPF solicitando o estabelecimento de medidas concretas que pudessem ser implementadas no sentido de incorporar esses conceitos neste tipo de projetos.

\section{Caracterização de uma adutora}

As condutas adutoras destinam-se ao transporte, quer gravítico, quer por elevação mecânica, de água para abastecimento dos aglomerados populacionais.

Existem diversos tipos de materiais empregues em condutas. Os ângulos de deflexão variam em função dos materiais empregues, mas nunca são muito elevados, o que significa que as mudanças de direção são geralmente feitas à custa de acessórios em curva. Os ângulos das curvas também variam em função do material utilizado.

Para assegurar o correto funcionamento das condutas são necessários órgãos de manobra e segurança como válvulas de seccionamento, ventosas e descargas de fundo. As válvulas de seccionamento têm como objetivo seccionar a conduta em troços mais pequenos, garantindo.se um menor volume de esvaziamento em situação de intervenção sobre as mesmas. As ventosas têm como função permitir a saída de ar sempre que este se acumule nas condutas, bem como permitir a entrada de ar quando é necessário esvaziar as mesmas. A sua instalação deve ser feita nos pontos altos, onde haja mudança de inclinação da conduta. As descargas de fundo têm como finalidade permitir o esvaziamento da conduta sempre que necessário, ou seja, em caso de avaria, manutenção ou operação, devendo, por isso, ser colocadas em todos os pontos baixos [1].

Os projetos de condutas adutoras são habitualmente constituídos, no que diz respeito aos desenhos, por plantas e perfis longitudinais (Figura 1), onde se representam o traçado e a altimetria da conduta, bem como as localizações das ventosas e das descargas de fundo (Figura 2).

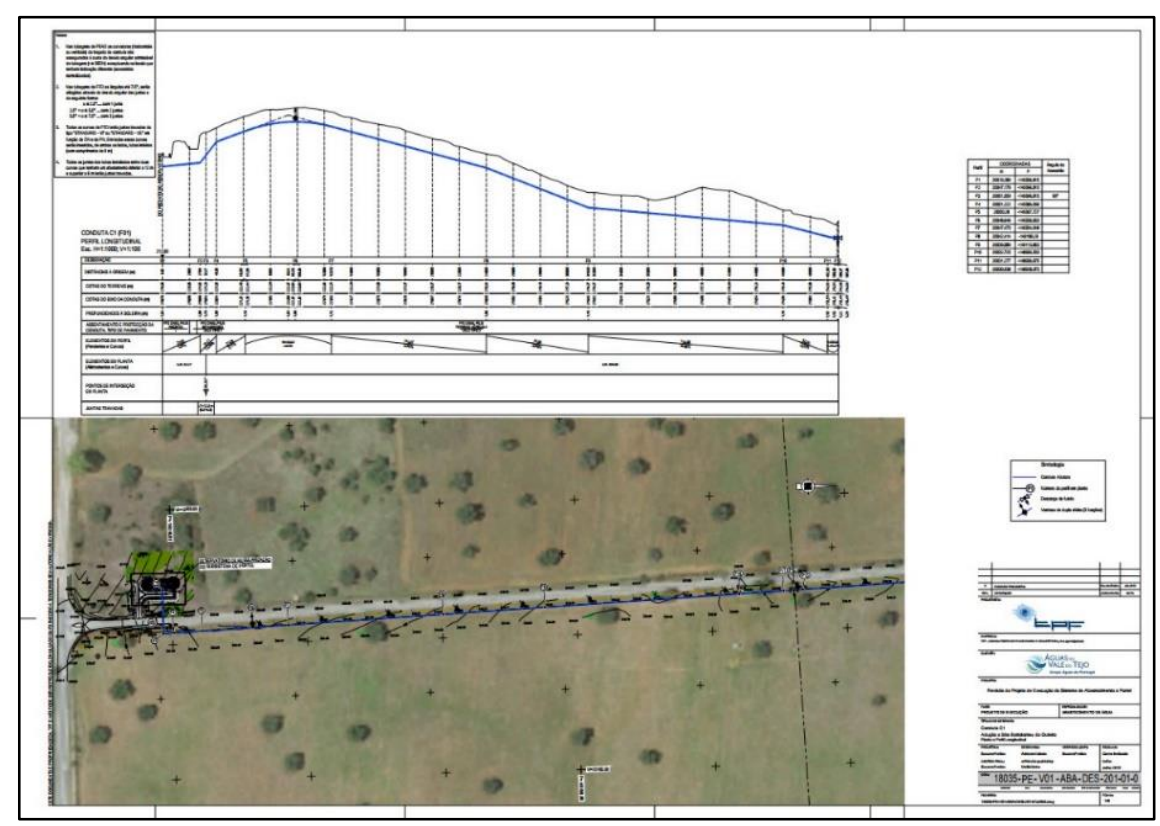

Figura 1: Exemplo de um desenho de projeto de uma conduta adutora. 


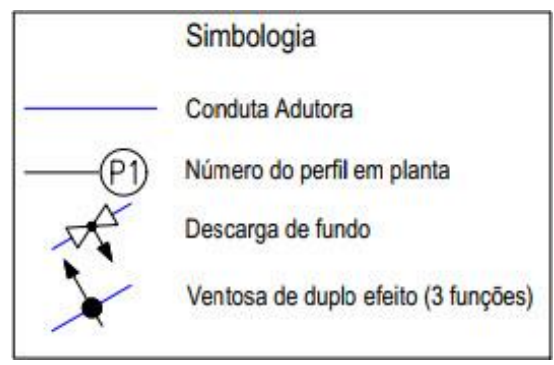

Figura 2: Simbologia.

Ao contrário do que acontece noutras obras lineares, nas condutas adutoras a relação entre a planta e o perfil não se estabelece pela sua quilometragem, mas antes pelos seus pontos notáveis, ou seja, pelos pontos que marcam uma alteração de alinhamento, em planta ou em perfil. Esses pontos são normalmente numerados de forma sequencial, independentemente da sua origem (planta ou perfil) (Figuras 3 e 4).

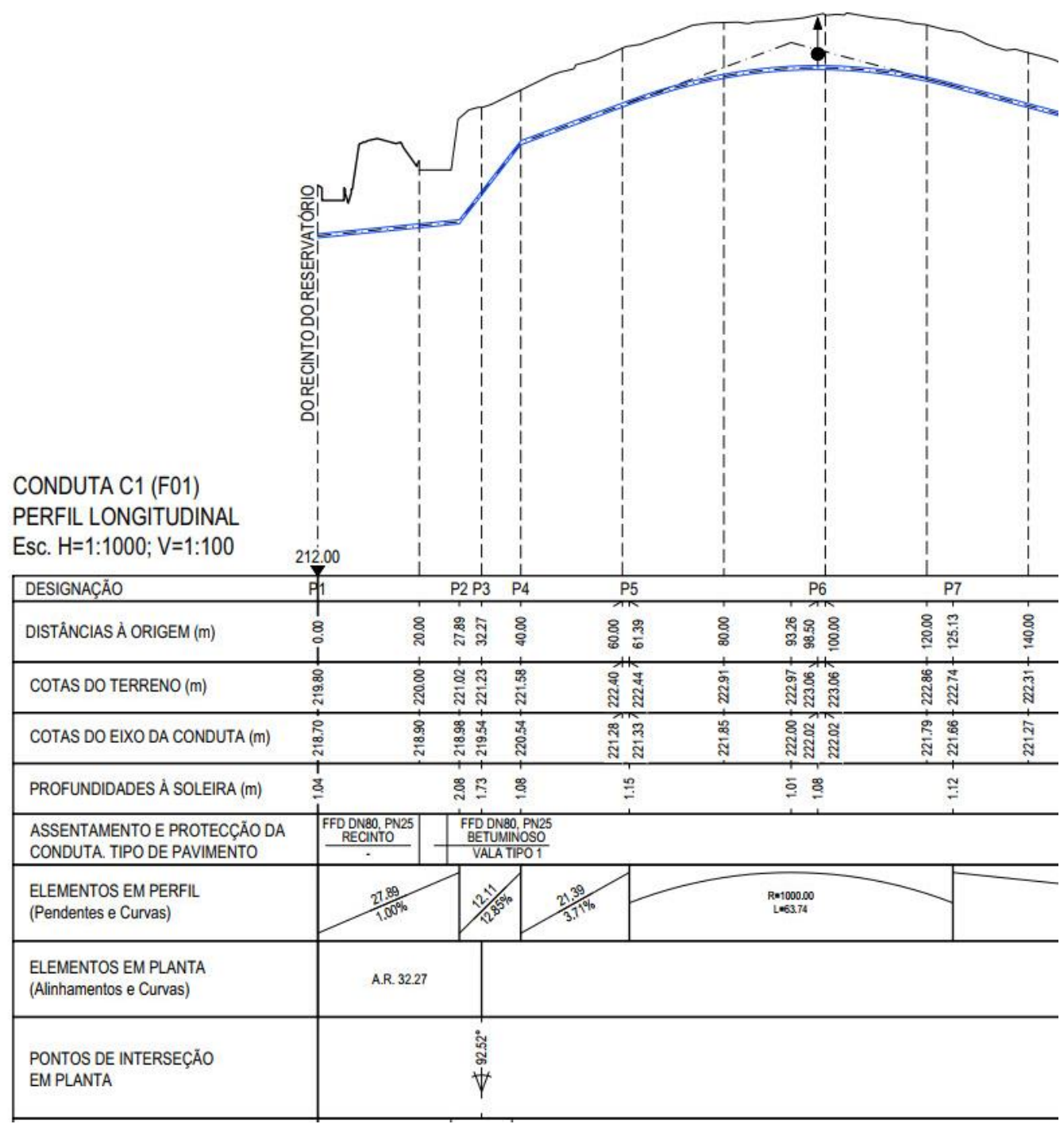

Figura 3: Pormenor de um perfil longitudinal de projeto de uma conduta adutora. 


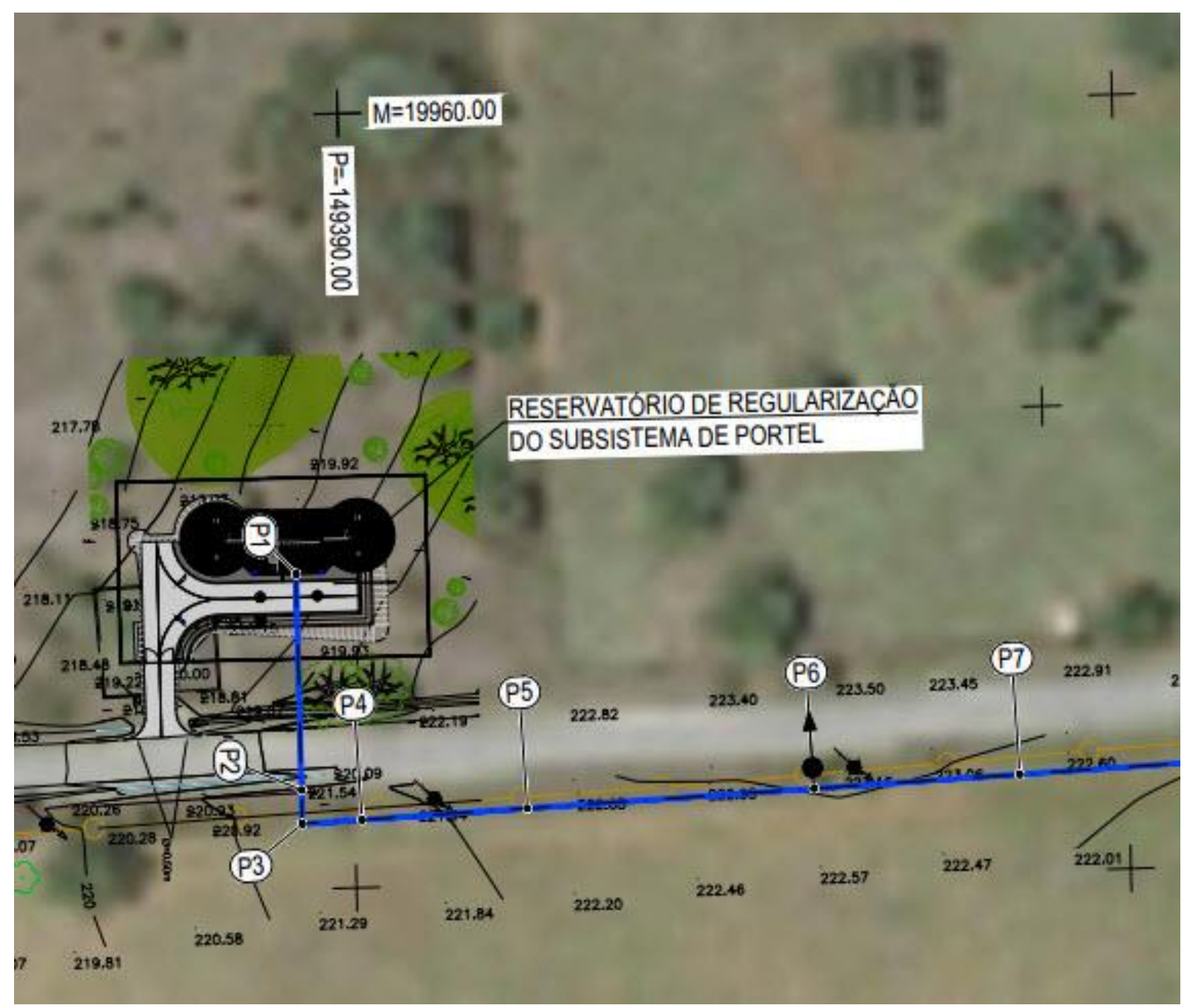

Figura 4: Pormenor de uma planta de projeto de uma conduta adutora.

É ainda habitual apresentar-se uma tabela com as coordenadas desses pontos, onde se identifica também o acessório comercial necessário (Figura 5). Adicionalmente, representam-se ainda os vértices das curvas em desenvolvimento, ou seja, a interseção dos alinhamentos do início e do fim da curva. Também neste caso é habitual apresentar de forma tabular as coordenadas destes pontos. 


\begin{tabular}{|c|c|c|c|}
\hline \multirow{2}{*}{ Perfil } & \multicolumn{2}{|c|}{ COORDENADAS } & \multirow{2}{*}{$\begin{array}{c}\text { Angulo do } \\
\text { Acessório }\end{array}$} \\
\cline { 2 - 3 } & $\mathrm{M}$ & $\mathrm{P}$ & \\
\hline P1 & 20019.289 & -149396.815 & \\
\hline P2 & 20047.179 & -149396.815 & \\
\hline P3 & 20051.559 & -149396.815 & $90^{\circ}$ \\
\hline P4 & 20051.222 & -149389.096 & \\
\hline P5 & 20050.28 & -149367.727 & \\
\hline P6 & 20048.646 & -149330.653 & \\
\hline P7 & 20047.473 & -149304.048 & \\
\hline P8 & 20042.414 & -149189.29 & \\
\hline P9 & 20039.089 & -149113.863 & \\
\hline P10 & 20032.725 & -148969.503 & \\
\hline P11 & 20031.277 & -148936.675 & \\
\hline P12 & 20030.938 & -148928.973 & \\
\hline
\end{tabular}

Figura 5: Tabela exemplificativa contendo as coordenadas dos perfis e o ângulo do acessório comercial.

\section{Funcionalidades nativas do Civil 3D}

O Civil 3D é um software utilizado para conceber, desenvolver e gerir projetos de engenharia civil, fundamentalmente nas áreas de terraplanagem e transportes. Este software está organizado por objetos. Os mais relevantes para o assunto em análise são: Surfaces, Alignments, Profiles e Profile Views (Figura 6).

As Surfaces permitem gerar um modelo digital do terreno, que servirá de suporte a todas as representações do terreno que sejam necessárias. Os Alignments permitem definir o traçado em planta, neste caso da conduta adutora. Os Profiles são as diferentes altimetrias associadas a um determinado Alignment, como por exemplo as cotas do terreno e as cotas da conduta. As Profile Views são cortes longitudinais pelos Alignments, onde se pode visualizar e editar os Profiles. Associadas às Profile Views existem as Bands, que compõem o pente e que preenchem automaticamente a informação geométrica.

O Civil 3D dispõe ainda de ferramentas que permitem gerar automaticamente as comumente designadas "folhas planta perfil", sendo para tal necessário definir as View Frames. A sua definição depende do Alignment e do modelo da folha, onde já estará definida a área destinada à planta e ao perfil, bem como as respetivas escalas. Ao gerar as folhas são criados Profile Views, parciais, sendo criado um para cada folha. Para além disso, o Civil 3D permite trabalhar o aspeto gráfico dos desenhos através da customização de estilos. 


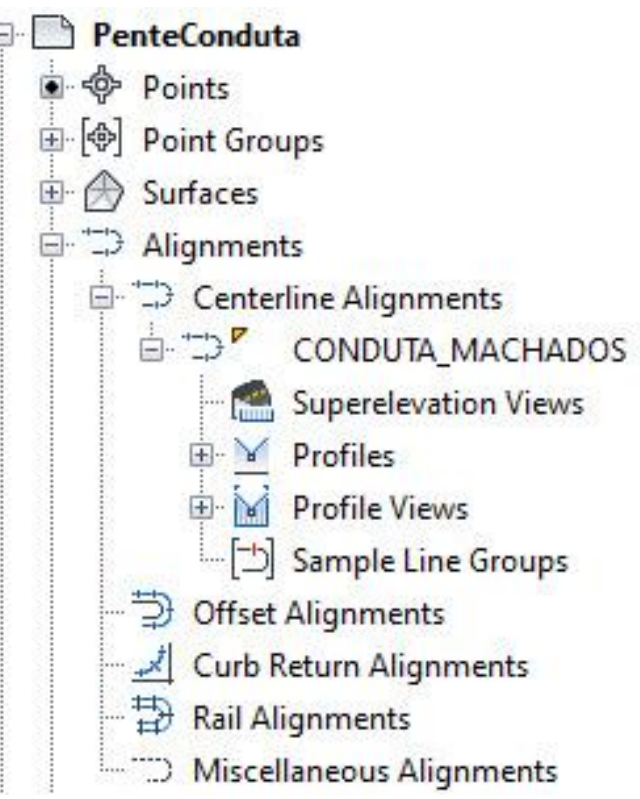

Figura 6: Estrutura de objetos do Civil 3D.

Todas estas ferramentas potenciam a utilização da metodologia BIM e permitem aumentar a produtividade da elaboração deste tipo de projetos, quando comparada com a metodologia tradicional, em CAD. Contudo, a incapacidade de identificar os pontos notáveis e os vértices é uma limitação significativa, que teria de ser contornada recorrendo à inserção manual dos textos, tanto nos perfis, como na planta, sem relação entre eles. O facto da necessidade da referida inserção manual é especialmente crítico pela dimensão habitual dos projetos de condutas adutoras, podendo facilmente chegar-se às centenas de pontos notáveis. Para além do referido, qualquer alteração na geometria da conduta que implicasse acrescentar ou eliminar um ponto notável ou um vértice num trecho cuja identificação estivesse concluída, implicava renomear todos os pontos notáveis a jusante desse novo ponto. Esta tarefa teria de ser realizada em triplicado, uma vez que seria necessário alterar a planta, o perfil e a respetiva tabela de coordenadas.

Para evitar todo este trabalho, foram concebidos desenvolvimentos em VBA que aproveitaram os objetos de Civil 3D e permitiram aplicar os conceitos BIM a estes aspetos particulares dos projetos de condutas adutoras que não são contemplados no Civil 3D.

\section{Funcionalidades desenvolvidas em VBA}

Numa descrição mais superficial, poder-se-ia afirmar que o que a macro desenvolvida executa de forma automática é colocar textos, blocos e tabelas no desenho. Todos estes elementos são CAD, mas a sua criação e posicionamento só é possível devido ao contexto proporcionado pelos objetos de Civil 3D, aos quais estes elementos CAD são associados pelas variáveis XData.

As funcionalidades da macro dividem-se em três grupos: pontos notáveis (perfis), vértices (das curvas em desenvolvimento) e órgãos de manobra (ventosas e descargas de fundo). Independentemente do que o utilizador pretende fazer, é-lhe solicitado que identifique o Alignment, o Profile da conduta e a Profile View (ver Figura 7). Como foi descrito 
anteriormente, tanto o Profile como a Profile View dependem do Alignment, pelo que depois da seleção do Alignment pretendido, já só aparecem na janela de seleção os Profiles e Profile Views que lhe estão associados.
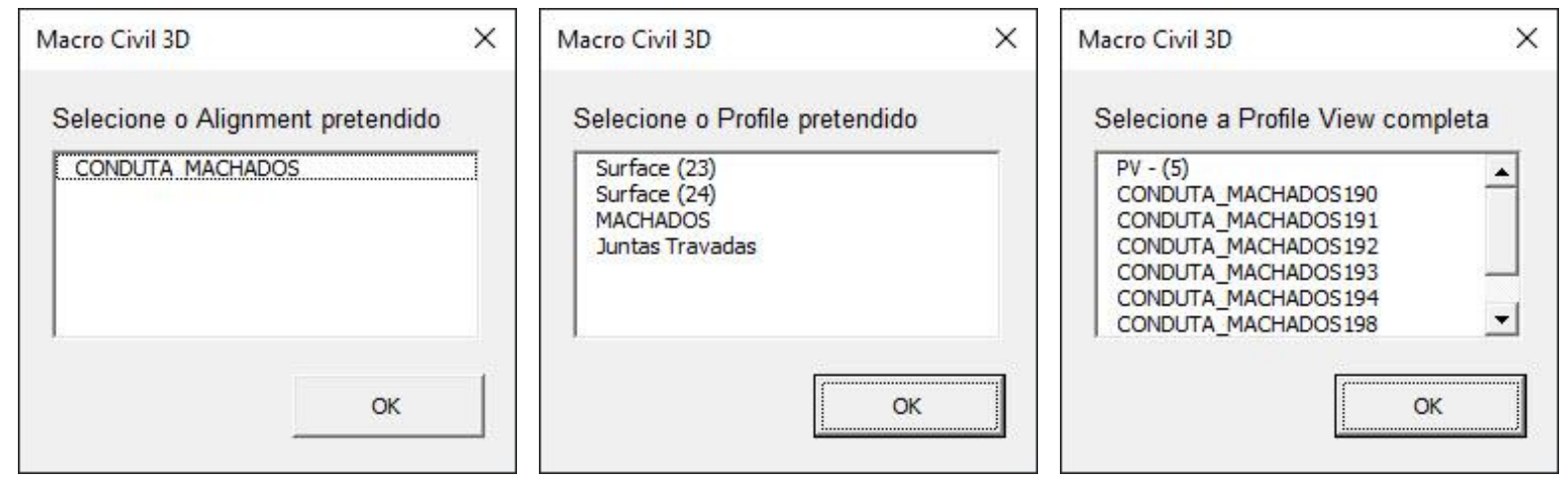

Figura 7: Identificação do Alignment, do Profile e da Profile View.

Depois de selecionado o Alignment, são identificados os pontos quilométricos (pks) e a direção do início de cada entidade. O Civil 3D identifica a última entidade, o que permite obter o pk e a direção do fim. As entidades são os diferentes troços que compõe o objeto, neste caso, o Alignment. As entidades do Alignment podem ser de 14 tipos diferentes: tangentes, arcos, espirais e grupos com diferentes combinações desses três tipos. No traçado de condutas adutoras utilizam-se apenas tangentes e arcos. No caso dos arcos recolhe-se adicionalmente informação relativa aos vértices, não só pk e direção, mas também coordenadas $\mathrm{M}$ e $\mathrm{P}$.

No caso do Profile o processo de recolha dos pks é semelhante, percorrendo-se as entidades do Profile para registar o pk do início de cada entidade. Neste caso as entidades podem ser de 4 tipos: tangentes, curvas circulares, parabólicas simétricas, ou assimétricas. $\mathrm{Na}$ macro consideraram-se apenas as tangentes e as curvas parabólicas simétricas. Nesta corrida é ainda verificada a necessidade de colocação de ventosas ou descargas de fundo. Para tal, no caso das tangentes, é avaliada a inclinação da entidade em análise e da anterior. Caso tenham sinais contrários, estamos na presença de um ponto alto, ou de um ponto baixo, o que significa que é necessário colocar um órgão de manobra. No caso das curvas, recorre-se à propriedade HighLowPointStation que indica o pk do ponto alto ou baixo, em função do tipo de curva: côncava ou convexa. Estes pontos só são considerados para a colocação de órgãos de manobra no caso de não coincidirem com os extremos da curva.

Depois de recolhidos os pks do Alignment e do Profile é necessário remover os repetidos, ou seja, aqueles que correspondem em simultâneo a pontos notáveis em planta e em perfil. Para tal, é necessário ordenar e arredondar os valores, para que valores iguais não sejam considerados distintos por acumulação de erros computacionais.

Antes de surgir o menu onde o utilizador seleciona as ações que pretende realizar, resta apenas determinar as coordenadas dos pks apurados.

Nesta fase já toda a informação está recolhida, restando apenas materializá-la no desenho. Para isso o utilizador terá de indicar o que pretende fazer. O menu organiza-se em três zonas: à esquerda, um conjunto de caixas de seleção, onde o utilizador pode escolher que partes do código é que quer correr; ao centro, uns botões para colocar manualmente órgãos de manobra, ou evitar que sejam colocados automaticamente, em localizações específicas; à direita, uma caixa de seleção para escolher o material da conduta e outra de texto para indicar a tolerância. 
Ambas as caixas se destinam à determinação do diâmetro comercial dos acessórios das curvas (Figura 8).

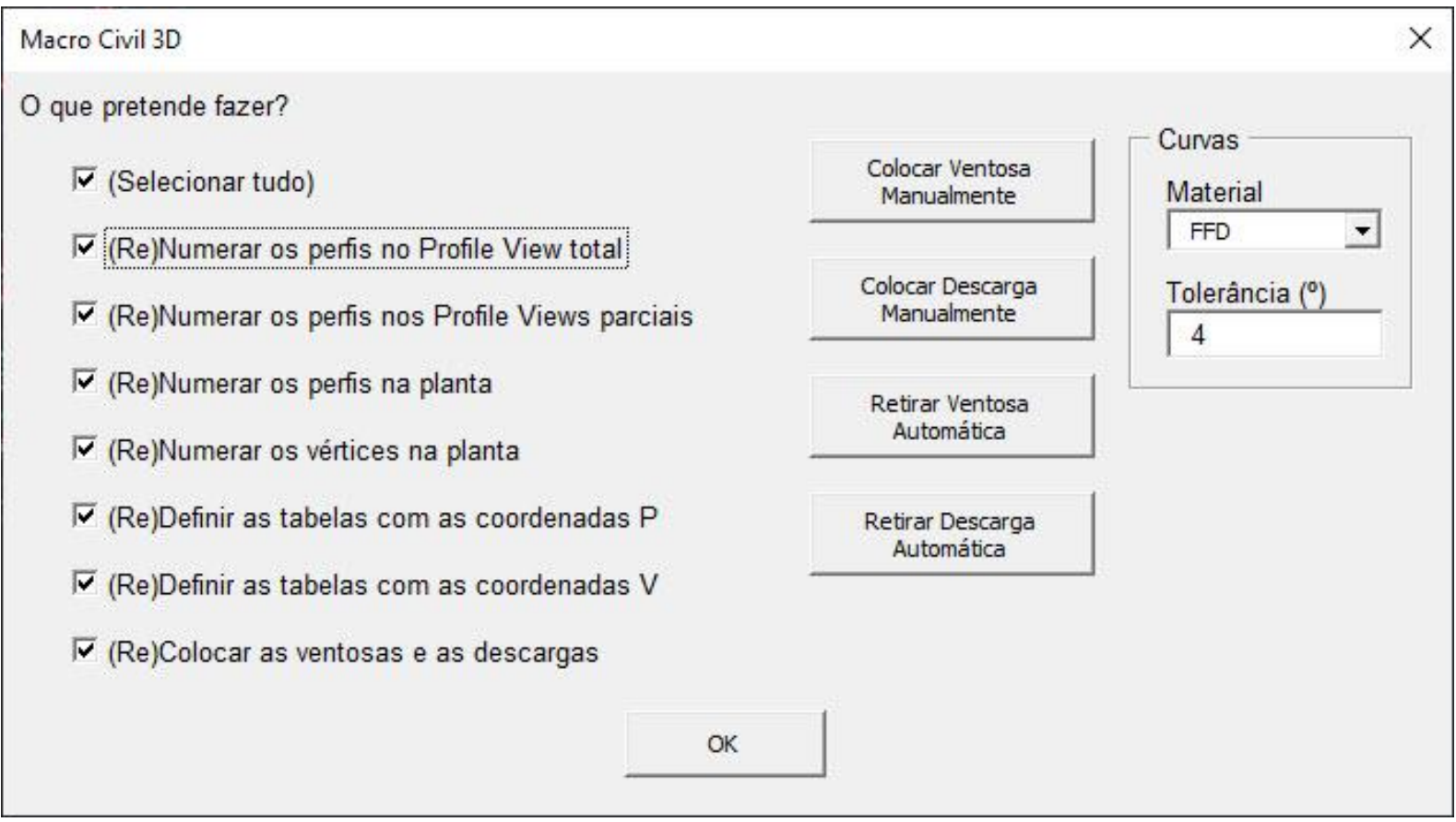

Figura 8: Menu da aplicação desenvolvida.

No que diz respeito às caixas de seleção, elas organizam-se da seguinte forma:

- Perfis
○ Profile View total
○ Profile View parcial
o Planta

- Vértices

○ Planta

- Coordenadas
○ Perfis
○ Vértices

- Órgãos de manobra

A macro foi pensada para poder ser executada várias vezes, isto é, para atualizar a informação sempre que haja necessidade de alterar a definição da conduta, que, como havia sido referido, pode obrigar a renomear os perfis, ou os vértices, ou acrescentar ou remover órgãos de manobra. Desta forma, é possível manter o desenho sempre coerente e atualizado, sem grande esforço. A estratégia adotada passou por associar os elementos geridos pela macro ao objeto de Civil 3D respetivo. A título de exemplo, as designações dos perfis na Profile View, para além de ficaram numa layer específica para este tipo de informação (0-GER-Pente (texto)-(Designação)), é-lhe atribuída uma variável XData com o nome da Profile View em que estão a ser colocados. Desta forma, numa próxima corrida da macro, é possível filtrar os textos pela layer e depois percorrer 
cada um deles verificando se pertencem à Profile View pretendida. Em caso afirmativo o texto é eliminado para que posteriormente possam ser colocados todos os textos válidos para o momento da corrida.

Refere-se que o procedimento descrito precisou de ser redefinido para o caso dos órgãos de manobra. Com efeito, apesar de haver regras claras para a identificação dos locais onde esses órgãos devem ser colocados, que possibilitam a colocação automática, houve necessidade de permitir ajustes manuais por parte da equipa projetista. Para esse efeito, foram criados os botões da parte central do menu, que permitem colocar blocos. A diferença entre colocar os blocos utilizando as ferramentas nativas e fazê-lo recorrendo à macro está nas variáveis XData que são associadas aos blocos no caso da macro e que permitem as funcionalidades acima descritas.

No caso de se querer acrescentar um órgão de manobra, a colocação de um bloco representativo desse órgão parece óbvia, mas no caso de se querer retirar um órgão colocado automaticamente, a colocação de outro bloco pode não ser tão evidente. De facto, ao colocar um bloco definido para não ser impresso no local onde se pretende remover o órgão de manobra colocado automaticamente, está-se a criar uma lista de pks onde não se pretendem órgãos de manobra. Essa lista será posteriormente confrontada com a lista dos pks dos órgãos de manobra definidos automaticamente, gerando uma terceira lista apenas com os pks sobrantes. Note-se que a edição das posições dos órgãos de manobra deverá ser feita exclusivamente na Profile View total, encarregando-se a macro de atualizar a planta e os perfis parciais.

Resta apenas abordar a questão das tabelas. Como foi referido, para além das coordenadas (M e P), as tabelas dos perfis contêm também os ângulos dos acessórios. A determinação do ângulo comercial correto é feita com a informação recolhida mais à direita do menu, ou seja, com a identificação do material da conduta e com a tolerância permitida. A macro está preparada para condutas em FFD e em PEAD. Para cada curva é identificado o ângulo comercial disponível para o material selecionado, identificando com um erro os ângulos que não se enquadram em nenhum dos intervalos associados aos acessórios comerciais. Uma outra funcionalidade associada à criação das tabelas está relacionada com o número de linhas a colocar em cada tabela. Idealmente deveria ser colocada uma tabela em cada folha, apresentando apenas os pontos relativos à folha onde se encontra. A macro permite fazer isto caso tenham sido geradas as View Frames. Ao gerar as View Frames, são também criadas Match Lines, que marcam a transição entre folhas. Recolhendo esta informação é possível determinar que pontos aparecem em que folhas e assim determinar em que linha partir cada tabela.

\section{Tempo de desenvolvimento}

A macro descrita no âmbito do presente artigo foi desenvolvida em 2018 em dois sprints: um em setembro de 32 horas e outro em dezembro de 46 horas, totalizando 78 horas de desenvolvimento. Em 2018 e 2019 foram registadas 22 horas de suporte, totalizando, assim, 100 horas de investimento nesta ferramenta.

Ainda não estão disponíveis métricas de utilização que permitam quantificar o tempo de recuperação do investimento feito no desenvolvimento da ferramenta, mas um dos utilizadores da empresa, que aplicou a macro a 4 condutas adutoras com $5,1 \mathrm{~km}, 3,7 \mathrm{~km}, 7,2 \mathrm{~km}$ e $6,9 \mathrm{~km}$, respetivamente, admite ter poupado uma semana de trabalho com a utilização da macro. 


\section{Desenvolvimentos futuros}

Está previsto a curto prazo tornar a macro mais robusta no que diz respeito à prevenção de erros, introduzindo verificações que garantam que os blocos e os estilos necessários à execução da macro se encontram no ficheiro sobre o qual a macro está a correr. Desta forma, espera-se reduzir o tempo de suporte do Núcleo de Inovação e, consequentemente, encurtar o tempo de execução da Produção. Para além disso, seria interessante que se automatizasse a colocação de válvulas de seccionamento.

Numa vertente mais abrangente, o desenvolvimento desta ferramenta permitiu que o Núcleo de Inovação explorasse a API do Civil 3D, estando agora mais consciente do que pode ser feito para superar algumas limitações do programa. Seria interessante que todas as metodologias que recorrem ao Civil 3D, nas diferentes áreas de atividade da TPF Consultores, fossem agora revistas à luz do novo conhecimento, em busca de potenciais otimizações.

\section{Conclusões}

A aposta no desenvolvimento da ferramenta descrita considera-se acertada, na medida em que o investimento foi relativamente baixo e a sua recuperação quase imediata. Para além disso, o potencial de encurtar os tempos de produção é elevado, tendo em conta que nos últimos 3 anos a TPF Consultores projetou cerca de $200 \mathrm{~km}$ de condutas adutoras. Admitindo que por cada $20 \mathrm{~km}$ de conduta se reduz uma semana de trabalho e que o volume de trabalho se mantém, é expectável que nos próximos 3 anos se poupem 10 semanas de trabalho.

Note-se que para além de permitir produzir mais rápido, a macro garante que os desenhos não têm erros associados aos pontos notáveis, aos vértices ou aos órgãos de manobra e que as plantas e os perfis estão coerentes no que diz respeito a estes elementos.

De referir, ainda, que esta ferramenta é aplicável ao projeto de todas as condutas em pressão, quer sejam adutoras de água ou condutas elevatórias de águas residuais.

Uma outra vantagem do desenvolvimento desta ferramenta foi tornar possível a utilização plena do Civil 3D. Sendo impensável, na era atual, executar manualmente as tarefas executadas pela macro, a TPF Consultores já tinha desenvolvido umas rotinas em Lisp que automatizavam parcialmente o processo, mas com uma necessidade de intervenção humana muito superior e que apenas funcionava em AutoCAD.

\section{Referências}

[1] A. Lencastre, Hidráulica Urbana e Industrial - Memórias Técnicas, Volume II, Lisboa: Laboratório Nacional de Engenharia Civil, 2003. 